\title{
Effects of irrigation solutions on corneal endothelial function
}

\author{
Mohamed I Yagoubi, W John Armitage, Jeremy Diamond, David L Easty
}

\begin{abstract}
Rabbit corneas were perfused in vitro with an irrigation solution for 90 minutes. This was followed by 6 hours of perfusion with tissue culture medium TC199 during which endothelial function was assessed by monitoring rates of swelling during a period of perfusion in the absence of bicarbonate ions, and subsequent rates of thinning when bicarbonate ions were restored to the perfusate. Corneal thickness (measured with an ultrasonic pachymeter) immediately following excision was 401 $\mu \mathrm{m}$ (SD 19, $\mathbf{n}=23$ ). During the 90 minute perfusion at $35^{\circ} \mathrm{C}$, corneas exposed to balanced salt solution (BSS), Hartmann's solution or $0.9 \% \mathrm{NaCl}$ (all initially at room temperature) swelled, respectively, at $14(\mathrm{SD} 2 \cdot 3, \mathrm{n}=4), 11$ (SD 2.6, $\mathrm{n}=4)$, and $70($ SD $4 \cdot 3, \mathrm{n}=4) \mu \mathrm{m} / \mathrm{h}$. Cold Hartmann's solution (initially at $4^{\circ} \mathrm{C}$ ) caused corneas to swell at $9(\mathrm{SD} 2 \cdot 3, \mathrm{n}=4)$ $\mu \mathrm{m} / \mathrm{h}$. On the other hand, corneas perfused with BSS Plus thinned at $9($ SD 3.4, $n=4) \mu \mathrm{m} / \mathrm{h}$ and TC199 with Earle's salts had little effect on thickness. Rates of swelling and thinning during the following assessment perfusion showed no apparent effects of prior exposure to any of the irrigation solutions on the barrier properties or pump function of the endothelium. Despite this, the increased thickness of corneas exposed initially to BSS, cold Hartmann's solution, or $0.9 \% \mathrm{NaCl}$ was not fully reversed, even by the end of the 6 hour assessment perfusion. In contrast, the swelling observed in corneas exposed to Hartmann's solution at room temperature was reversed and these corneas had returned to their normal thickness by the end of the assessment period. All corneas, even those exposed to $0.9 \% \mathrm{NaCl}$, had an intact endothelial mosaic with no evidence of damage or cell loss, although morphological differences in cell shape and the
\end{abstract}

Table 1 Composition of irrigation solutions and aqueous humour

\begin{tabular}{|c|c|c|c|c|c|c|}
\hline & $\begin{array}{l}\text { Aqueous } \\
\text { humour }\end{array}$ & $\begin{array}{l}\text { TC199 } \\
\text { Earle's }\end{array}$ & $\begin{array}{l}\text { TC199 } \\
\text { Hank's }\end{array}$ & $\begin{array}{l}\text { Hartmann's } \\
\text { solution }\end{array}$ & BSS & BSS Plus \\
\hline $\begin{array}{l}\mathrm{Na}^{+}(\mathrm{mM}) \\
\mathrm{K}^{+}(\mathrm{mM}) \\
\mathrm{Ca}^{2+}(\mathrm{mM}) \\
\mathrm{Mg}^{2+}(\mathrm{mM}) \\
\mathrm{Fe}^{3+}(\mathrm{mM}) \\
\mathrm{Cl}^{-}(\mathrm{mM}) \\
\mathrm{HCO}_{3}^{-}(\mathrm{mM}) \\
\mathrm{NO}_{3}{ }^{-}(\mathrm{mM}) \\
\mathrm{H}_{2} \mathrm{PO}_{4}^{-}(\mathrm{mM}) \\
\mathrm{HPO}^{2-}(\mathrm{mM}) \\
\mathrm{SO}_{4}^{2-}(\mathrm{mM}) \\
\text { Acetate }(\mathrm{mM}) \\
\text { Citrate }(\mathrm{mM}) \\
\text { Lactate }(\mathrm{mM}) \\
\text { Glucose }(\mathrm{mM}) \\
\text { Glutathione } \\
\text { Osmolality }(\mathrm{mosmol} / \mathbf{k g}) \\
\text { pH (20 })\end{array}$ & $\begin{array}{l}162 \cdot 9 \\
2 \cdot 2-3 \cdot 9 \\
1 \cdot 8 \\
1 \cdot 1 \\
\overline{-} \\
131 \cdot 6 \\
20 \cdot 2 \\
- \\
\overline{0} \cdot 6 \\
- \\
- \\
\overline{2} \cdot 5-4 \cdot 5 \\
2 \cdot 7-3 \cdot 7 \\
1 \cdot 9 \mu M \\
304 \\
7 \cdot 4\end{array}$ & $\begin{array}{c}144 \cdot 0 \\
5 \cdot 4 \\
1 \cdot 9 \\
0 \cdot 8 \\
1 \cdot 8 \\
123 \cdot 7 \\
26 \cdot 2 \\
1 \cdot 8 \\
1 \cdot 0 \\
- \\
0 \cdot 8 \\
0 \cdot 6 \\
- \\
\overline{5} \cdot 6 \\
0 \cdot 2 \mu M \\
290 \\
7 \cdot 4\end{array}$ & $\begin{array}{c}138 \cdot 0 \\
5 \cdot 8 \\
1 \cdot 3 \\
0 \cdot 8 \\
1 \cdot 8 \\
143 \cdot 7 \\
\overline{1} \cdot 8 \\
0 \cdot 4 \\
0 \cdot 3 \\
0 \cdot 8 \\
0 \cdot 6 \\
- \\
\overline{5} \cdot 6 \\
0 \cdot 2 \mu \mathrm{M} \\
288 \\
7 \cdot 4\end{array}$ & $\begin{array}{c}131 \cdot 0 \\
5 \cdot 0 \\
2 \cdot 0 \\
\overline{-} \\
11 \overline{1} \cdot 0 \\
\overline{-} \\
\overline{-} \\
\overline{-} \\
\overline{-} \\
\overline{29} \\
\overline{-} \\
\overline{-} \\
25 \overline{7} \\
6 \cdot 0\end{array}$ & $\begin{array}{c}144 \cdot 0 \\
10 \cdot 0 \\
4 \cdot 3 \\
3 \cdot 2 \\
\overline{-} \cdot 2 \\
127 \cdot 2 \\
- \\
- \\
- \\
- \\
\overline{28 \cdot 6} \\
5 \cdot 8 \\
- \\
- \\
\overline{-} \\
302 \\
7 \cdot 3\end{array}$ & $\begin{array}{c}160 \cdot 0 \\
5 \cdot 0 \\
1 \cdot 0 \\
1 \cdot 0 \\
\overline{1} \cdot 0 \\
130 \cdot 0 \\
25 \cdot 0 \\
- \\
\overline{3} \cdot 0 \\
\overline{-} \\
\overline{-} \\
\overline{5} \cdot 0 \\
0 \cdot 3 \mathrm{mM} \\
305 \\
7 \cdot 4\end{array}$ \\
\hline
\end{tabular}

appearance of cell borders were evident compared with freshly isolated cornea. (Br f Ophthalmol 1994; 78: 302-306)

Damage to the corneal endothelium through trauma or use of inappropriate irrigation solutions can compromise the long term success of intraocular surgical procedures. The efficacy of irrigation solutions, especially when used for extended periods, is critically dependent on their composition. Dikstein and Maurice ${ }^{1}$ showed in 1972 that perfusion of rabbit cornea with a Ringer solution containing bicarbonate ions, glucose, adenosine, and reduced glutathione (GBR) maintained endothelial pump function in vitro for several hours. Further work by McCarey and Edelhauser ${ }^{2}$ showed that this solution preserved endothelial function and ultrastructure better than earlier intraocular irrigation solutions.

Edelhauser's group ${ }^{2-6}$ subsequently tested several solutions commonly used for irrigation during intraocular sugery, including $0.9 \%$ sodium chloride, Plasmalyte 148, lactated Ringer's solution (Hartmann's solution), GBR, balanced salt solution (BSS), and BSS Plus (Alcon). They found that corneal thickness and endothelial structure were best maintained by solutions containing glutathione and bicarbonate. A number of clinical studies confirmed the efficacy of BSS Plus, a commercially available intraocular irrigation solution that contains glutathione and bicarbonate ions. ${ }^{7-10}$ Although BSS Plus appeared to cause less oedema immediately following intraocular surgery, ${ }^{11}$ an advantage in terms of reduced postoperative loss of endothelial cells was less clear cut. ${ }^{12}{ }^{13} \mathrm{~A}$ major problem has been to develop a stable solution containing a sufficient concentration of bicarbonate ions that is suitable for intraocular surgery. For example, GBR ${ }^{1}$ must be equilibrated with $5 \% \mathrm{CO}_{2}$ to give a stable $\mathrm{pH}$ of $7 \cdot 4$, which is clearly impractical for clinical use, and BSS Plus comes as a two part solution that is mixed immediately before use.

Previous assessments of intraocular irrigation solutions were made mainly on the basis of corneal thickness changes during exposure to the various solutions. The aim of our study, therefore, was to assess irrigation solutions in vitro not only by their capacity for maintaining thickness of rabbit corneas, but by evaluating functional integrity of the corneal endothelium after exposure to the irrigation solutions. This was done during a standardised period of perfusion by measuring swelling and thinning rates of corneas, respectively, in the absence and presence of bicarbonate ions. ${ }^{14}$ Endothelial morphology was also examined following perfusion. 


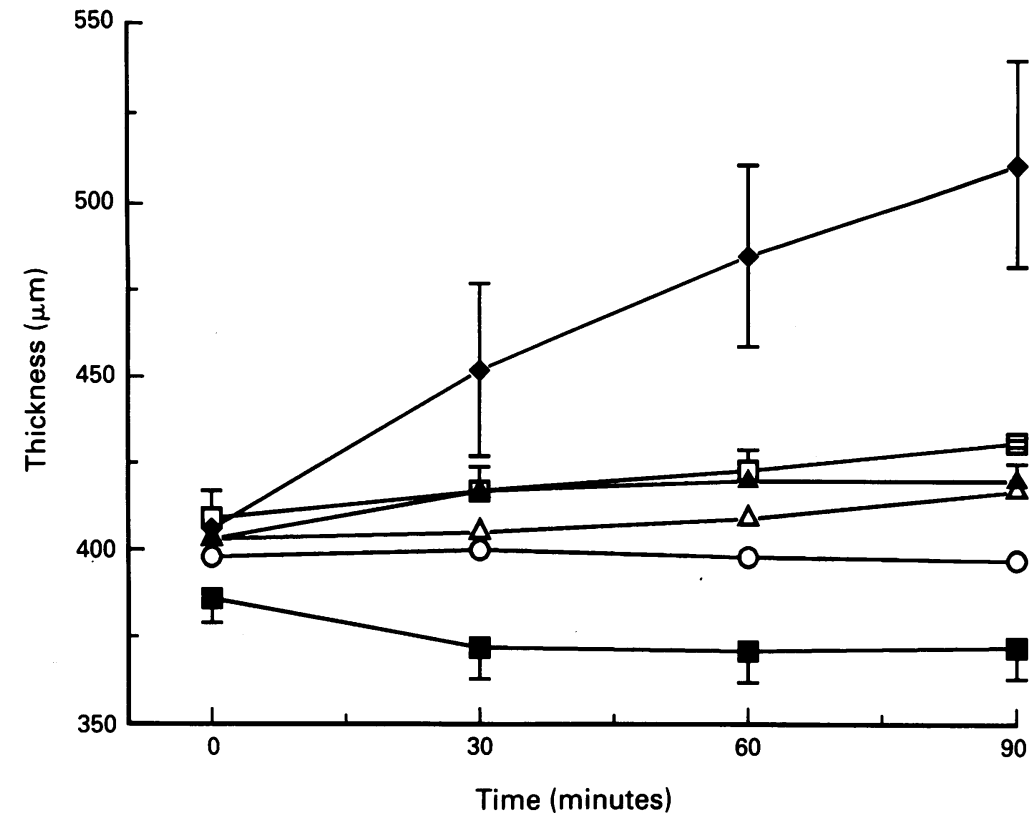

Figure 1 Change in corneal thickness (mean (SEM), $n=4)$ during initial 90 minutes' perfusion with irrigation solutions: TC199 with Earle's salts (O), BSS Plus ( $\square), B S S(\square)$,

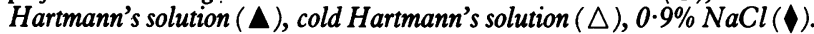

\section{Methods}

PREPARATION OF CORNEAS

Corneas obtained from New Zealand White rabbits (3-4 kg) after an intravenous overdose of pentobarbitone sodium were secured on support rings and perfused as described by Dikstein and Maurice. ${ }^{1}$ Corneal thickness, measured with an ultrasonic pachymeter (DGH Technologies, Inc), immediately following enucleation was 404 $\mu \mathrm{m}(\mathrm{SD} 28, \mathrm{n}=23)$. Excision of the cornea and mounting on the support ring had no effect on corneal thickness, which remained at $401 \mu \mathrm{m}$ (SD 19, $\mathrm{n}=23, \mathrm{p}=0.7$ paired $t$ test). The epithelial surface was covered with silicone oil to prevent changes in corneal thickness owing to evaporation.

The endothelial surface was perfused at $2 \cdot 5$ $\mathrm{ml} / \mathrm{h}$, a pressure of $15 \mathrm{~cm} \mathrm{H} \mathrm{H}_{2} \mathrm{O}$ and $35^{\circ} \mathrm{C}$. During the first 90 minutes of perfusion, corneas were exposed to an intraocular irrigation solution. This was followed by a further 6 hours of perfusion during which endothelial function was assessed.

\section{IRRIGATION SOLUTIONS}

The following solutions were evaluated: sterile, pyrogen free $0.9 \%(\mathrm{w} / \mathrm{v}) \mathrm{NaCl}$ (Manorpark

Table 2 Change in corneal thickness during exposure to irrigation solutions

\begin{tabular}{|c|c|c|c|}
\hline Irrigation solution & $\begin{array}{l}\text { Initial } \\
\text { thickness } \\
(\mu m)^{\star}\end{array}$ & $\begin{array}{l}\text { Rate of } \\
\text { change in } \\
\text { thickness } \\
(\mu \mathrm{m} / \mathrm{h}) t\end{array}$ & p Value \\
\hline $\begin{array}{l}0.9 \% \mathrm{NaCl} \\
\text { BSS } \\
\text { Hartmann's solution } \\
\text { Hartmann's solution (cold) } \\
\text { TC199 Earle's } \\
\text { BSS Plus }\end{array}$ & $\begin{array}{l}406(15) \\
409(16) \\
403(11) \\
403(34) \\
398(18) \\
386(14) \\
\mathrm{p}=0.7 \text { NS }\end{array}$ & $\begin{array}{r}+69 \cdot 7(4 \cdot 3) \\
+14 \cdot 2(2 \cdot 3) \\
+10 \cdot 6(2 \cdot 6) \\
+9 \cdot 4(2 \cdot 3) \\
-0 \cdot 8(2 \cdot 2) \\
-9 \cdot 3(3 \cdot 4)\end{array}$ & $\begin{array}{l}<0.001 \\
0.001 \\
0.003 \\
0.004 \\
0.72 \mathrm{NS} \\
0.025\end{array}$ \\
\hline
\end{tabular}

* Mean (SD), $n=4 ;$ †regression coefficient (SD), $n=4:$ + indicates swelling, - indicates thinning; łone way analysis of variance -
Pharmaceuticals), Hartmann's solution (lactated Ringer's solution, Baxter), balanced salt solution (BSS, Torbay Hospital Pharmaceutical Unit), BSS Plus (Alcon) and tissue culture medium TC199 with Earle's salts but without phenol red (Sigma, M3769). The composition of these solutions is given in Table 1 .

Corneas were perfused for 90 minutes with one of the irrigation solutions, and corneal thickness was measured with the ultrasonic pachymeter every 30 minutes. The silicone oil was removed briefly to allow the measurements to be made. Each measurement was the mean of readings taken at four different sites of the central cornea.

To mimic the conditions during intraocular surgery, corneas were initially exposed to the irrigation solutions at room temperature for the first few minutes of perfusion. For the remainder of the $\mathbf{9 0}$ minute perfusion, the water jacket in contact with the perfusion chamber warmed the solution to $35^{\circ} \mathrm{C}$. To evaluate the effects of using refrigerated irrigation solutions, a further group of corneas was exposed to Hartmann's solution at $4^{\circ} \mathrm{C}$. As with the solutions initially at room temperature, the majority of this perfusion was at $35^{\circ} \mathrm{C}$.

\section{ENDOTHELIAL ASSESSMENT}

Corneal hydration and, thus, thickness are controlled by the endothelium through a pump leak mechanism. Removal of bicarbonate ions from the perfusate suppresses endothelial pump function and causes corneal swelling, although inhibition of the pump is not complete unless $\mathrm{CO}_{2}$ is also removed from the perfusate. Pump function can be restored and the swelling reversed by returning bicarbonate to the perfusate. ${ }^{14}$

After the 90 minute perfusion with one of the irrigation solutions, endothelial function was, therefore, assessed during a further 6 hours of perfusion with TC199. Corneal thickness was measured every 30 minutes with the ultrasonic pachymeter. The first 2 hours of perfusion were with TC199 with Earle's salts (Sigma, M3769). This solution contained sodium bicarbonate (26 $\mathrm{mmol} / \mathrm{l}$ ) and glutathione, and should have supported endothelial pump function. Two hours of perfusion with TC199 with Hanks' salts (Sigma, M3274) then followed. This solution did not contain bicarbonate ions and, thus, should have caused corneal swelling, although the solution was not $\mathrm{CO}_{2}$ free. For the final 2 hours, perfusion with TC199 Earle's was restored and, providing that the endothelium was undamaged, corneas should have thinned. Neither of the TC199 solutions contained phenol red, and their measured osmolalities (Roebling osmometer) were 290 and $288 \mathrm{mosmol} / \mathrm{kg}$, respectively, for TC199 with Earle's salts and TC199 with Hanks' salts.

Rates of change in corneal thickness both during perfusion with the irrigation solutions and during the three parts of the assessment perfusion were determined by regression analysis. Comparisons were made between groups by analysis of variance at the $5 \%$ level of significance. 


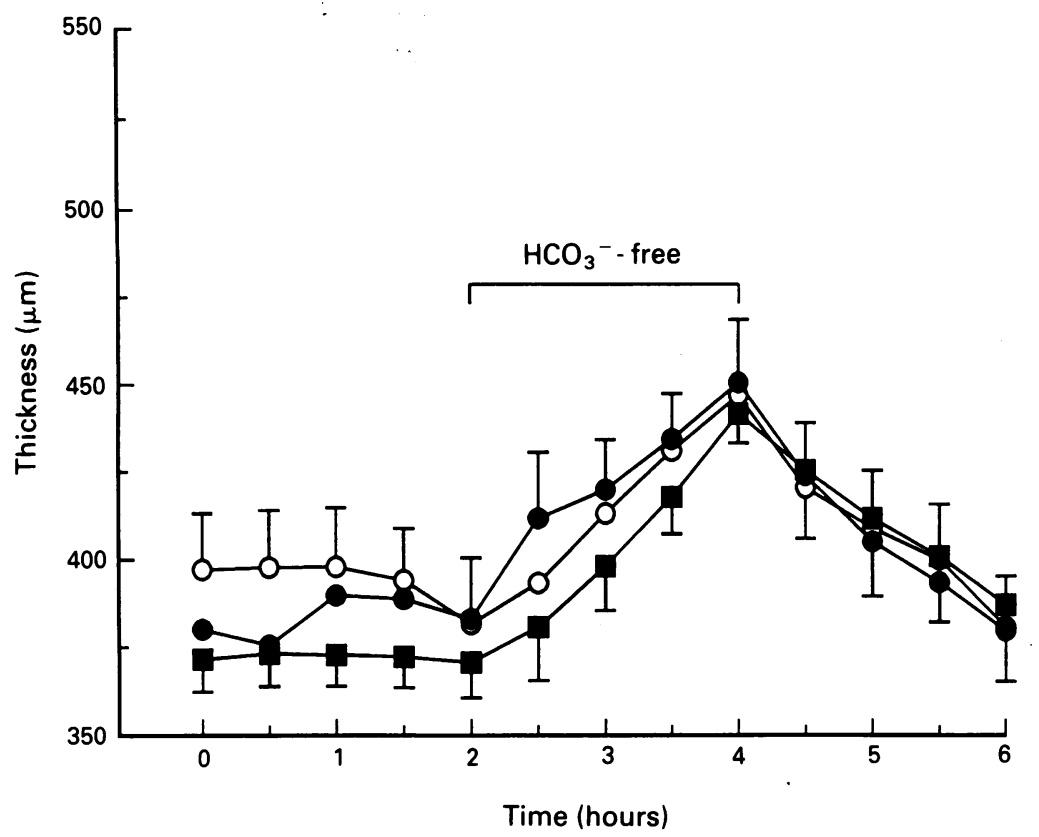

Figure 2 Change in corneal thickness (mean (SEM), $n=4$ ) during assessment perfusion following 90 minutes' exposure to irrigation solutions: untreated control (O), TC199 with Earle's salts (O), BSS Plus (ם).

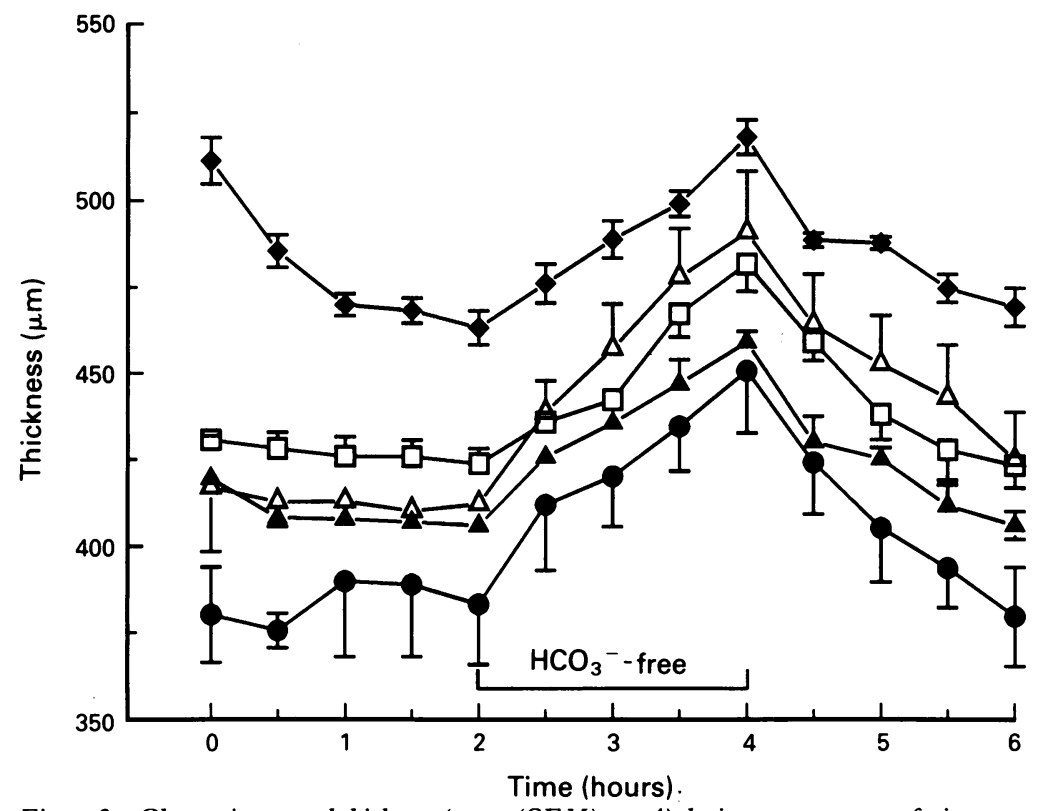

Figure 3 Change in corneal thickness (mean $(S E M), n=4$ ) during assessment perfusion following 90 minutes' exposure to irrigation solutions: untreated control (O), BSS ( $\square)$, Hartmann's solution ( $\triangle)$, cold Hartmann's solution $(\triangle), 0.9 \% \mathrm{NaCl}(\triangleleft)$.

Table 3 Changes in corneal thickness during the 6 hour assessment perfusion with TC199

\begin{tabular}{|c|c|c|c|}
\hline \multirow[b]{2}{*}{ Irrigation solution ${ }^{\star}$} & \multicolumn{3}{|c|}{ Rate of change in corneal thickness $(\mu \mathrm{m} / \mathrm{h}) t$} \\
\hline & $\begin{array}{l}\text { TC199 Earle's } \\
0-2 h\end{array}$ & $\begin{array}{l}\text { TC199 Hank'sf } \\
2-4 h\end{array}$ & $\begin{array}{l}\text { TC199 Earle's } \\
4-6 \mathrm{~h}\end{array}$ \\
\hline $\begin{array}{l}\text { Untreated control } \\
0.9 \% \mathrm{NaCl} \\
\text { Hartmann's solution } \\
\text { Hartmann's solution (cold) } \\
\text { BSS } \\
\text { TC199 Earle's } \\
\text { BSS Plus }\end{array}$ & $\begin{array}{l}+3 \cdot 9(24 \cdot 3) \\
-22 \cdot 7(4 \cdot 9) \\
-5 \cdot 7(7 \cdot 8) \\
-2 \cdot 5(5 \cdot 6) \\
-3 \cdot 3(4 \cdot 6) \\
-6 \cdot 9(8 \cdot 0) \\
-0 \cdot 5(2 \cdot 1)\end{array}$ & $\begin{array}{l}+31 \cdot 5(2 \cdot 0) \\
+26 \cdot 6(7 \cdot 1) \\
+25 \cdot 5(2 \cdot 7) \\
+39 \cdot 4(12 \cdot 8) \\
+29 \cdot 5(9 \cdot 6) \\
+33 \cdot 6(18 \cdot 5) \\
+35 \cdot 8(7 \cdot 4)\end{array}$ & $\begin{array}{l}-34 \cdot 5(5 \cdot 5) \\
-22 \cdot 4(8 \cdot 4) \\
-24 \cdot 9(4 \cdot 9) \\
-30 \cdot 7(3 \cdot 8) \\
-29 \cdot 7(7 \cdot 2) \\
-30 \cdot 5(7 \cdot 7) \\
-26 \cdot 7(2 \cdot 4)\end{array}$ \\
\hline
\end{tabular}

${ }^{\star}$ Corneas, except for untreated controls, were perfused for 90 minutes with an irrigation solution before the assessment perfusion with TC199; tregression coefficient (SD), n=4: + indicates swelling

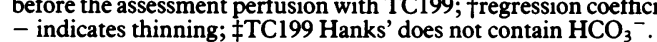

ENDOTHELIAL MORPHOLOGY

After perfusion, the endothelium was stained with trypan blue and alizarin red $S$ and examined by light microscopy after brief fixation in $2.5 \%$ glutaraldehyde $(0 \cdot 15 \mathrm{~mol} / \mathrm{l}$ cacodylate buffer,
$3 \mathrm{mmol} / \mathrm{C} \mathrm{Ca}^{2+}$ ) for 10 minutes. ${ }^{15}$ The alizarin red $\mathrm{S}$ was adjusted to $\mathrm{pH} 4 \cdot 2$ before use.

\section{Results}

EXPOSURE TO IRRIGATION SOLUTIONS

Changes in corneal thickness during perfusion for 90 minutes with the irrigation solutions are shown in Figure 1 and Table 2. There were no differences in corneal thickness between the various groups at the start of perfusion $(p=0 \cdot 7)$. Exposure to TC199 with Earle's salts resulted in little change in thickness, whereas BSS Plus caused thinning. Corneas exposed to the other solutions all increased in thickness during the $\mathbf{9 0}$ minute perfusion. Corneas exposed to $0.9 \%$ $\mathrm{NaCl}$ swelled at by far the highest rate. Hartmann's solution and BSS caused modest, though significant, increases in thickness (Table 2).

ASSESSMENT OF ENDOTHELIAL FUNCTION

Freshly isolated corneas not subjected to the 90 minute perfusion with an irrigation solution (untreated control) maintained their thickness during the first 2 hours of perfusion with TC199 with Earle's salts. When perfused with bicarbonate free TC199 with Hanks' salts, they swelled at $31.5 \mu \mathrm{m} / \mathrm{h}(\mathrm{SD} 2 \cdot 0, \mathrm{n}=4)$, but thinned again at $34.5 \mu \mathrm{m} / \mathrm{h}(\mathrm{SD} 5 \cdot 5, \mathrm{n}=4)$ when reperfused with TC199 with Earle's salts.

An extra 90 minute perfusion with TC199 with Earle's salts preceding the assessment perfusion had no effect on corneal thickness at the start of the assessment nor on the rates of swelling and thinning during the three parts of the assessment perfusion (Fig 2 and Table 3). The changes in thickness of corneas previously exposed to BSS Plus were also similar to the controls.

In spite of the swelling induced by prior exposure to BSS and cold Hartmann's solution, the rates of swelling and thinning during the assessment were no different from the controls at the $5 \%$ level of significance (Fig 3 and Table 3 ). These corneas, however, were still thicker than controls $(p=0.01)$ at the end of the assessment perfusion.

The only groups to thin significantly during the first 2 hours of the assessment perfusion with TC199 were those previously exposed to $0.9 \%$ $\mathrm{NaCl}$ (regression coefficient $-22 \cdot 7 \mu \mathrm{m} / \mathrm{h}$, $\mathrm{p}<0.001$ ) or to Hartmann's solution at room temperature (regression coefficient $-5.7 \mu \mathrm{m} / \mathrm{h}$, $\mathrm{p}=0.02)$. By the end of the assessment, corneas exposed to $0.9 \% \mathrm{NaCl}$ were still considerably thicker than the controls $(p=0.01$, Fig 3$)$, whereas corneas exposed to room temperature Hartmann's solution were no different from the controls at the $5 \%$ level of significance.

ENDOTHELIAL MORPHOLOGY

Staining with trypan blue and alizarin red S demonstrated in all cases an intact endothelial mosaic with no evidence of cell loss or damage, even in corneas exposed to $0.9 \% \mathrm{NaCl}$. Some changes were apparent, however, both to cell shape and to the intercellular borders compared 

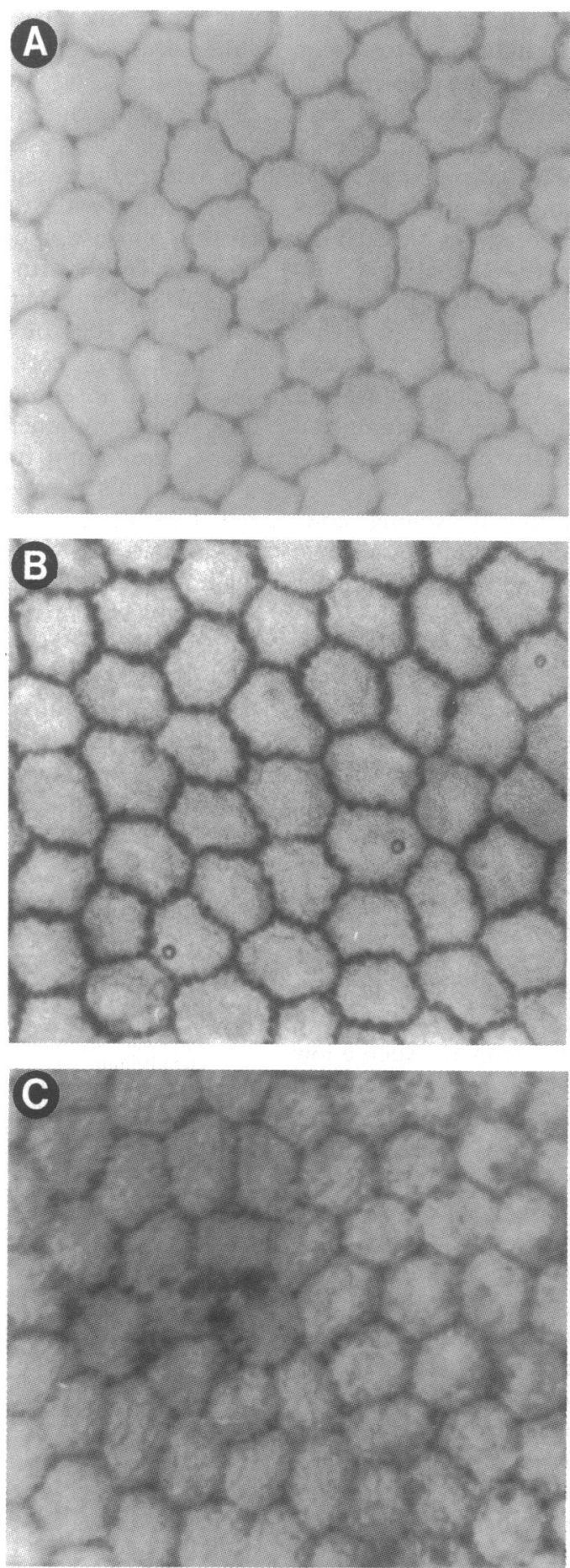

with freshly isolated cornea (Fig 4). Cells exposed to Hartmann's solution had broader and more irregular borders, whereas cells exposed to BSS were rounder and showed more regular, smoother borders than freshly isolated, unperfused corneas. Cells exposed to BSS Plus and TC199 were similar to each other in appearance, with somewhat straighter and wider borders than unperfused corneas. Although the nuclei of cells exposed to $0.9 \% \mathrm{NaCl}$ were prominent, this was not the result of trypan blue staining. The borders of these cells were very straight and sharply defined (Fig 4E).

\section{Discussion}

Previous investigations of the effects of intraocular irrigation solutions on corneas have
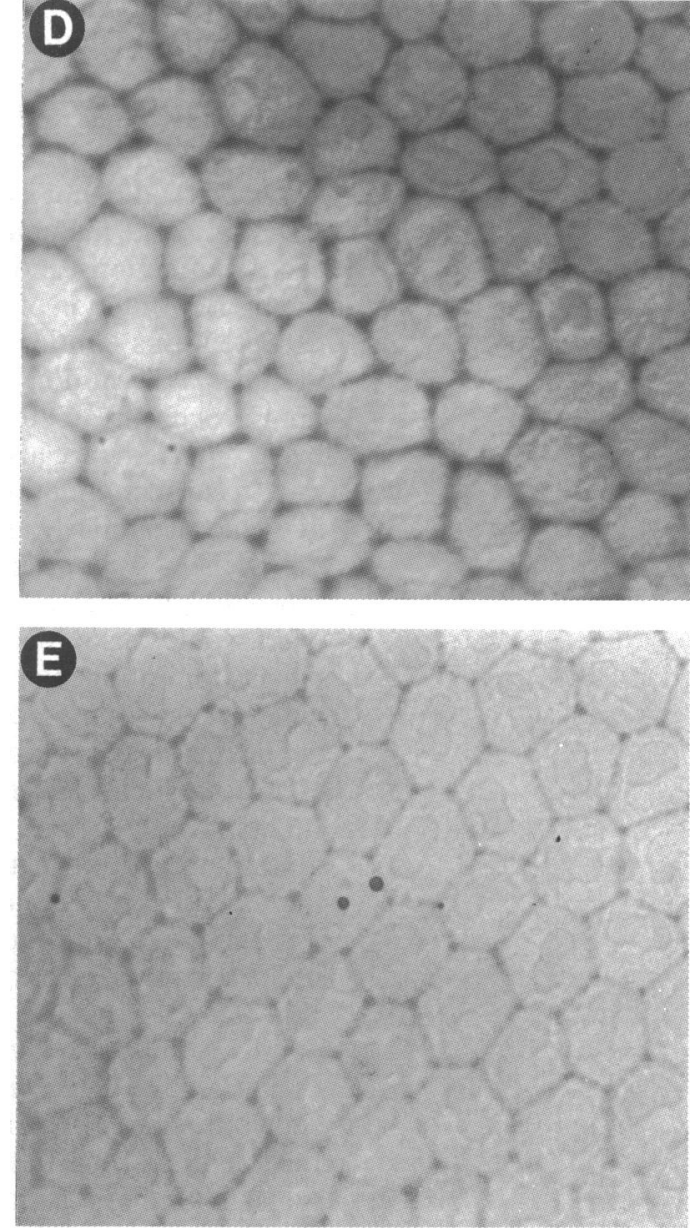

Figure 4 Endothelial morphology after staining with trypan blue and alizarin red $S$. (A) Freshly isolated, untreated cormea. $(B)$ Cornea perfused with Hartmann's solution for 90 minutes, followed by 6 hour assessment perfusion - note thickened borders. (C).Cornea perfused with BSS Plus for 90 minutes, followed by 6 hour assessment perfusion-borders wider and straighter than $(A)$. (D) Cornea perfused with $B S S$ for 90 minutes, followed by 6 hour assessment perfusion - note more rounded shape of cells and straighter borders than $(A)$. (E) Cornea perfused with $0.9 \% \mathrm{NaCl}$ for 90 minutes, followed by 6 hour assessment perfusion - nuclei are prominent (though not stained with trypan blue), and borders very straight and sharply defined.

focused mainly on corneal thickness changes during exposure to the various solutions..$^{2-6}$ The present study extends those observations through the addition of a standardised period of perfusion following exposure to the irrigation solutions, during which the ability of the endothelium to control corneal hydration was assessed.

Corneal hydration, and hence thickness, is the result of a balance between the passive leak of water and solute across the endothelium into the stroma, and the activity of endothelial ion pumps. The leak, in turn, is dependent on the stromal swelling pressure and the passive permeability of the endothelial monolayer. Disruption of endothelial intercellular junctions or failure to support the endothelial ion pumps will, therefore, lead to corneal swelling. ${ }^{14}$ 
Control of corneal hydration during exposure to irrigation solutions is influenced by ionic composition of the solution, the presence of energy substrates, and factors such as osmolality and $\mathrm{pH}$. Of the irrigation solutions we used, only $0.9 \% \mathrm{NaCl}$ did not contain calcium, which is essential for maintaining endothelial intercellular junctions and, hence, for maintaining the barrier function of the endothelial layer. ${ }^{16} \mathrm{As}$ expected, this solution caused a rapid increase in thickness $(70 \mu \mathrm{m} / \mathrm{h})$ of rabbit corneas. One hour's exposure to $0.9 \% \mathrm{NaCl}$ has previously been reported to cause irreversible damage to rabbit corneal endothelium, ${ }^{3}$ but we found no evidence of similarly extensive damage either on the basis of subsequent endothelial function or morphology. Such a high rate of swelling, however, would make this solution an inappropriate choice for intraocular irrigation, especially for extended surgical procedures.

Hartmann's solution and BSS both lack $\mathrm{HCO}_{3}{ }^{-}$, which is essential for endothelial pump function, an energy substrate (glucose), and glutathione. Both of these solutions caused an increase in corneal thickness; but, given its low osmolality ( $257 \mathrm{mosmol} / \mathrm{kg}$ ), the rate of swelling in Hartmann's solution was much lower than expected. Hartmann's solution also has a low $\mathrm{pH}$ of only 6 and a slightly lower ionic strength than BSS $(0.143 v 0.163$, respectively). It has been shown that both $\mathrm{pH}$ and ionic strength influence the swelling properties of cornea and that reductions in both these factors reduce the rate of swelling of isolated bovine stroma. ${ }^{17}$ Such a low $\mathrm{pH}$ has been shown to be harmful to corneal endothelium, ${ }^{18}$ and irreversible changes following exposure to Hartmann's solution have also been reported ${ }^{5}$; but those detrimental changes were observed after longer exposure times than the 90 minutes used in the present experiments.

The changes in corneal thickness during the assessment perfusion suggested that neither BSS nor Hartmann's solution irreversibly disrupted the endothelial barrier properties or pump function. However, the swelling induced by exposure to BSS and cold Hartmann's solution was not fully reversed by the end of the assessment period, although they were still thinning and may well have attained their original thickness with continued perfusion. In contrast, corneas exposed to Hartmann's solution at room temperature did return to their normal thickness within the time course of the experiment, suggesting that if irrigation solutions are to be stored in a refrigerator, they should be allowed to warm to room temperature before use.

Tissue culture medium 199 with Earle's salts and BSS Plus both contain $\mathrm{HCO}_{3}^{-}$as well as glucose and glutathione, which are all components that have been identified as necessary for maintenance of corneal thickness. ${ }^{1}$ Although the osmolality of TC199 was lower than that of human aqueous humour (Table 1), rabbit corneas maintained their thickness during perfusion with this solution, while they thinned during exposure to BSS Plus. The assessment perfusion confirmed that endothelial function was apparently unaffected by prior exposure to either of these two solutions, but, as with the other irrigation solutions, morphological changes to the endothelium were evident. These changes, however, seemed to have no functional significance for the endothelium.

In summary, the two solutions that contained $\mathrm{HCO}_{3}{ }^{-}$, glucose, and glutathione - namely, BSS Plus and TC199 with Earle's salts, did not cause corneal swelling. On the other hand, exposure to $0.9 \% \mathrm{NaCl}, \mathrm{BSS}$, or Hartmann's solution, all of which caused corneal swelling to varying degrees, did not subsequently appear to have any deleterious consequences for endothelial barrier properties or pump function. All of the irrigation solutions caused some morphological changes to cell shape or to intercellular borders, but there was no evidence of cell loss or gross disruption to the endothelial mosaic. These changes had no apparent functional significance. The swelling induced by cold Hartmann's solution was more persistent than that following exposure to Hartmann's solution at room temperature, suggesting that refrigerated irrigation solutions should be warmed before use.

We thank Alcon Laboratories for their generous support of these experiments.

1 Dikstein S, Maurice DM. The metabolic basis to the fluid pump in the cornea. 7 Physiol 1972; 221: 29-41.

2 McCarey BE, Edelhauser HF, Van Horn DL. Functional and structural changes in the corneal endothelium during in vitro perfusion. Invest Ophthalmol 1973;12:410-7.

3 Edelhauser HF, Van Horn DL, Hyndiuk RA, Schultz RO Intraocular irrigating solutions: their effect on the corneal endothelium. Arch Ophthalmol 1975; 93: 648-57.

4 Whikehart DR, Edelhauser HF. Glutathione in rabbit cornea endothelia: the effect of selected perfusion fluids. Inves Ophthalmol Vis Sci 1978; 17: 455-64.

5 Edelhauser HF, Gonnering R, Van Horn DL. Intraocular irrigating solutions: a comparative study of BSS Plus and lactated Ringer's solution. Arch Ophthalmol 1978; 96: 51620.

6 McDermott, Snyder R, Slack J, Holley G, Edelhauser HE. Effects of intraocular irrigants on the preserved human Effects of intraocular irrigants on the preserv

7 Moorehead LC, Redburn DA, Merritt J, Garcia CA. The effects of intravitreal irrigation during vitrectomy on the electroretinogram. Am $\mathcal{F}$ Ophthalmol 1979; 88: 239-45.

8 Burke MJ, Parks MM, Calhoun JH, Diamond JG, de Faller JM. Safety evaluation of BSS plus in pediatric intraocular surgery. F Pediatr Ophthalmol Strabismus 1981; 18: 45-9.

9 Matsuda M, Tano Y, Edelhauser HF. Comparison of intraocular irrigating solutions used for pars plana vitrectomy and prevention of endothelial cell loss. $\mathcal{F}$ p $\mathcal{F}$ Ophthalmol 1984; 28: $230-8$

10 Glasser DB, Matsuda M, Ellis JG, Edelhauser HF. Effects of intraocular irrigating solutions on the corneal endothelium after in vivo anterior chamber irrigation. Am $\mathcal{F}$ Ophthalmol 1985; 99: 321-8.

11 Benson WE, Diamond JG, Tasman W. Intraocular irrigating solutions for pars plana vitrectomy: a prospective, randomized, double blind study. Arch Ophthalmol 1981; 99: 1013-5.

12 Kramer KK, Thomassen T, Evaul J. Intraocular irrigating solutions: a clinical study of BSS Plus and dextrose bicarbonate lactated Ringer's solution. Ann Ophthalmol 1991; 23: 101-5.

13 Rosenfeld SI, Waltmann SR, Olk RJ, Gordon M. Comparison of intraocular irrigating solutions in pars plana vitrectomy. Ophthalmology 1986; 93: 109-14.

14 Hodson S, Miller F. The bicarbonate ion pump in the endothelium which regulates the hydration of rabbit cornea. f Physiol (London) 1976; 263: 563-77.

15 Taylor MJ, Hunt CJ. Dual staining of corneal endothelium with trypan blue and alizarin red $\mathrm{S}$ : importance of $\mathrm{pH}$ for the dye-lake reaction. Br 7 Ophthalmol 1981; 65: 815-9.

16 Kaye GI, Mishima S, Cole JD, Kaye NW. Studies on the cornea. VII Effects of perfusion with Ca-free medium on corneal endothelium. Invest Ophthalmol 1968; 7: 53-66.

17 Elliott GF, Goodfellow JM, Woolgar AE. Swelling studies of bovine corneal stroma without bounding membranes. bovine corneal stroma without boung
f Physiol (London) 1980; 298: 453-70.

18 Gonnering R, Edelhauser HF, van Horn DL, Durant W. The $\mathrm{pH}$ tolerance of rabbit and human corneal endothelium. Invest Ophthalmol Vis Sci 1979; 18: 373-90. 